\title{
2 Language, Pedagogy, and Active Participant Engagement
}

\author{
Gaze in the Multilingual Landscape
}

Elana Shohamy and Alastair Pennycook

\section{Introduction}

This chapter points to several current ways in which linguistic landscape (LL) research has been expanding - a wider geopolitical scope, a broader semiotics, an ethnographic understanding of signs in place, and an emphasis on pedagogical affordances - towards a focus on pedagogy, awareness, and activism. Building on the work of Lanza and her collaborators (Blackwood, Lanza and Woldemariam 2016; Lanza and Woldemariam 2014), and the geopolitical and interpretive extensions they have brought to the field of LL, we point in this chapter to the significance of pedagogical action in relation to LLs, where students learn how to observe, notice, engage, and critically interpret the LL, with potential for developing student activism. Several approaches to LLs have raised the question of active participant engagement. At one level, this is a question of the interpretive element as LLs only have meaning when people make sense of the embedded signs. At another level, however, this has involved a more pedagogical focus, investigating ways in which the LL can be used by learners in schools to promote critical awareness of multilingual spaces (Hayik 2017).

In this chapter we take these questions further by looking at how students can become more aware of social and linguistic injustices and inequalities in the landscape but also engage in corrective transformative actions of the landscape. What is perceived in the LL is highly dependent on the positionality of the viewer - the linguistic, political, racial, or ethnic gaze through which people read the landscape - and thus what is proposed for change is dependent on both what is seen and how corrective action is understood. This has implications for multilingual educational policies, the ways students perceive mutual ownership of public space, and the role LL pedagogies can play in developing activist student engagement focused on social change. In the first part of the chapter, we provide a brief overview of developments in LL research. This is followed by a discussion of three studies of the LL in Israel that raise questions about awareness, injustice, and activism with regard to inclusion, equality, and justice. The subsequent discussion raises questions about activism, pedagogy, and the student gaze. 


\section{Elana Shohamy and Alastair Pennycook}

\section{Geopolitical, semiotic, ethnographic, and pedagogical extensions}

From its central focus on linguistic signs in public spaces and the relation between identifiable languages in the environment and wider domains of multilingualism and language policy, LL research has expanded in several directions: The geopolitical, semiotic, ethnographic, and pedagogical. The first has been an opening up to both global and Southern perspectives. From its inception, LL has focused predominantly on languages found on signage in public places, where the "linguistic" refers principally to named languages or textual inscriptions, the "landscape" denotes the public space in which these signs occur, and the geopolitical domain has been predominantly in the global North. While this linguistic-textual orientation has itself expanded toward multiple languages and modalities, studies from the global South expanded the scope in important ways (Blackwood, Lanza and Woldemariam 2016). Of importance from this perspective are studies of how languages, such as English (particularly through various brand names and their appropriation), in cities, such as Addis Ababa (Lanza and Woldemariam 2014), have been perceived as prestigious, and how such perceptions are linked to social and economic aspirations and the functions of language in late modernity.

A second expansion has taken the landscape as the primary focus and asks how such material spaces can be viewed in semiotic terms. While this distinction is not always clear (as with all the distinctions here, these developments are neither linear nor discreet), in its strongest form this approach to LL reverses the priorities of the language-in-the-landscape framework by developing a landscape-as-language framework, potentially eschewing any reference to named languages. This, then, is a focus on the landscape itself as a set of signs, where landscape is foreground rather than background, signs are semiotic items rather than forms of public signage, and the term "language," if it is used, may be an umbrella term for social semiotics rather than referring to particular linguistic varieties. Not only has LL research from this perspective made salient a wide range of public spaces - streets, and virtual spaces - but it has shifted the focus of study towards a broad semiotics that includes graffiti, transport, and mobility (Pennycook 2009, 2019; Karlander 2018), multimodal analyses of monuments (Waksman and Shohamy 2016), tattoos and embodiment (Peck and Stroud 2015), smells (Pennycook and Otsuji 2015), and other interpretable domains, such as markets (Lou 2017). From this perspective, the "linguistic" in the LL focuses not so much on named languages and scripts as on a wide array of social semiotic resources (Shohamy 2015).

A third expansion has raised the question of the processes by which we interpret LL texts. As broader discussions of text and discourse analysis have suggested, we cannot rely solely on textual analysis to understand 
meaning, and we need to get beyond the idea that "a chunk of discourse has only one function and one meaning" (Blommaert 2005, 34). This position raises several concerns for LL research, suggesting that discourse analysis of language in public space alone will never suffice: We need an ethnographic understanding of how texts got there, what work they do, and who reads them. Rather than making assumptions about authorial intent, it is important to include the context of a sign; the history of the place where it is displayed; the intended audience; social, cultural, and political institutions; the reactions of passers-by; and customers (whether signs are intended for them or not) (Malinowski 2009; Trumper-Hecht 2010). Blommaert (2013, 107) therefore urges the use of ethnographic understandings of the LL: we have to account for "complexity as an empirical feature of sociolinguistic superdiversity." The LL is part of our social fabric, produced, deciphered, lived in, resisted, and a site of identity formation and contestation (Williams and Lanza 2016). Different religious LLs in Addis Ababa presented by the Ethiopian Orthodox Church - a marker of national identity - and Protestant religious communities - subsequently introduced to Ethiopia by foreign missionaries - serve as a platform for evangelization, contestation, debate, and understanding (Woldemariam and Lanza 2012).

A final development (though this overview is not intended in such a short space to be comprehensive) addresses the educational possibilities of LL projects. Different projects have ranged from using the LL as a source of linguistic input to developing critical awareness of school and neighbourhood multilingualism (and the disparities between the two) (Dagenais et al. 2009; Gorter and Cenoz 2015; Malinowski 2015). Sending students out to document the LLs that surround them can bring much deeper awareness of languages in the environment as well as afford significant learning opportunities back in the classroom. Intervening in educational spaces (shifting from monolingual to multilingual LLs), it has been shown, can have major effects on children, families, school policies, and educational possibilities (Menken, Rosario and Valerio 2018). The pedagogical possibilities afforded by critical LL awareness open up questions about why certain languages are present or absent, which link to questions of immigration, ethnic suburbs, discrimination, marginalization of minorities, and languages within a wider set of political and economic relations (Hayik 2017). For Shohamy and Waksman $(2009,314)$, LLs not only provide a site for research but also enable sites for "critical pedagogy, activism, and language rights." Building on these developments in LL research and pedagogy, we now turn specifically to questions of critical language awareness and activism.

\section{From critical language awareness to critical language activism}

It is into this expanded LL space that this chapter now moves by looking at research that examines how students can become more aware of social and linguistic injustices in the landscape and how they can engage in changing 


\section{Elana Shohamy and Alastair Pennycook}

these landscapes. A key element of many of the pedagogical orientations to LL is critical language awareness (CLA), which Alim, focusing on contexts of language use in the USA, explains as helping students become aware of the ways in which education and other institutions "silence diverse languages in White public space by inculcating speakers of heterogeneous language varieties into what are, at their core, White ways of speaking and seeing the word/world, that is, the norms of White, middleclass, heterosexist males" (Alim 2005, 28). The relations of language, race, gender, ethnicity, and religion in the Israeli contexts that we will be examining in this chapter are different, and yet the general concerns remain the same: Critical exposure to various LLs is an effective tool for noticing social, political, and linguistic injustices.

These first two studies examined language awareness among tertiary students in Israel. The studies showed the potential for LL pedagogies to develop increased language-political awareness. One study (Shohamy and Abu Ghazaleh Mahajneh 2012) focused on the reactions of university students toward the LL in their academic studies at a major university in Israel. While Arabic and Hebrew are displayed in their hometowns, and Arabic is the language of instruction in their schools, when they come to the university they are faced with a situation where Hebrew is the only language of instruction and English is the language of academic texts; Arabic does not exist. Almost all the LL signs on campus are in Hebrew, some are in English, and there are hardly any signs in Arabic. In the study by Shohamy and Abu Ghazaleh Mahajneh (2012), the attitudes and reactions of Arab students towards these language representations were assessed via interviews. The students felt that Arabic should have a more important role to play, as it was completely marginalized and overlooked.

They said that the university needs to translate the signs for Arab students in order to show respect, even if students understand the meaning of signs written in Hebrew. One of the students explained, "I understand the meaning of the signs, but prefer that these signs will be translated in order to provide us with some rights at the university." Another student said that signs in Arabic are important since "more than a fifth of the students at this university are Arabs"; further, a student argued that "translation is necessary since it is a sign of respect and the least they can do." One student wrote that putting the signs in Arabic grants legitimacy to its speakers and shows that Arab students are an integral part of the university. The Arab students accepted the dominance of Hebrew but believed that displaying the signs on campus in Arabic would show that the university grants them respect, empowerment, legitimacy, recognition, rights, belonging, and symbolic value.

Half of the students noted that the lack of Arabic in public spaces at the university should be interpreted as a violation of their human and personal rights. The students also reacted to electronic signs and especially to aural announcements, such as those heard over the loudspeakers in the library 
and the students' housing area. They felt their cultural identity was diminished since the lack of Arabic implied marginalization. An interesting finding was that the students were pessimistic about the future and could not see how the situation would ever change. This view about the future, they noted, led them to become less active and engaged in taking any steps to try and affect change in the signs on campus. The bilingual Hebrew/English policy reinforces and confirms their feelings that this is a permanent reality that will never change. This view can be interpreted as a sign that they internalized their inferior status in relation to a "Jewish Israeli" at the university, that they do not really count and have no participatory role to play. In other words, while the Shohamy and Abu Ghazaleh Mahajneh study was able to show students' awareness of the discriminatory LL at the university, it did not suggest an increased sense of activism. It suggested in fact just the opposite: A tendency to surrender to the perceived reality and comply with de facto policy rather than act.

In the second study of students in Israel, Goldstein-Havazki (2011) examined the development of LL awareness by Arab high-school students. Ten Arab students were each asked to document 15 signs in the neighborhood in Jaffa where they reside. Jaffa is part of the mixed city of Tel Aviv-Jaffa; most Arab-Israelis in the city live in the Jaffa section, making up about a third of the population there. The students were given pre- and post-survey questionnaires about the visibility of Arabic, Hebrew, and English in their neighborhoods. They were then asked to analyze and reflect on LL representation in the area. The main finding was that, contrary to what the students thought at the beginning of the study - that Arabic would be a dominant language in their neighborhoods in Jaffa given the large number of Arabic residents living there - Arabic had very low representation in the LL in the public space in relation to Hebrew and even English, even among the shop owners some of whom are their own close relatives.

This awareness - originating from engagement with actual data which they themselves were trained to collect and document - does not simply stop at a level of understanding. It also produced a range of affective and ideological responses. There were feelings of frustration when the full extent of the lack of Arabic became apparent: "I don't have any comments because look, from all of the signs I analyzed, this was (the only) restaurant sign which was written in Arabic and in Hebrew." Some were at least able to notice the positive in the occasional multilingual usage: "Only Mr. Buckhary, whose sign on his private medical clinic was in three languages, English, Hebrew, and Arabic, this made me very pleased!" Students also raised questions about the hierarchical relations among languages in Israel. One student, reacting to a danger sign where Arabic was displayed in the last place noted: "And I ask myself why is English written before Arabic? Arabic is the second official language in Israel, isn't that so? And I live in a city where all inhabitants or most of them are Arabs or Arabic speakers." For some students, it was a question of respect: "If Hebrew and English appear on the sign, at least 


\section{Elana Shohamy and Alastair Pennycook}

they should add Arabic for the Arab inhabitants so they will understand the point of respect." For others, it was a question of exclusion, as if the Arabicspeaking community was not concerned with certain questions; in response to a sign in Jaffa presented only in Hebrew asking residents not to pollute the environment, one student asked: "Environmental protection also isn't related to Arabs???"

For some of these students, this turned into resentment and criticism of their own community as they realized that even Arab-Israelis gave in to the hegemony of Hebrew: "Most of the store-owners in Jaffa are Arabs, so why don't they put Arabic on the sign of their stores? We are proud to be Arabs, so why don't we show the whole world that we are proud Arabs?" Some provided quite explicit criticisms of the ways they saw their own community had taken on board not just dominant state ideologies concerning languages but also broader language ideologies. For example, one said:

Yefet is the main street in Jaffa or the longest and most known to everybody. Instead of keeping this place as an Arabic area, we change our language and prefer to write the signs in Hebrew to attract more customers and that the sign will turn to everyone, with the fact that most of the customers are Arabs from Jaffa who understand Arabic very well.

This is a private sign that a person from Jaffa decided in which language this sign should be written, without any involvement of the state. This means that even Arabs slowly began to think that Hebrew was more beautiful and better, and sometimes they were ashamed of Arabic (translated from Hebrew).

Another student offered an analogy that indeed links these language ideologies to Alim's (2005) discussion of critical language awareness and race in the USA (above):

This research reminds me of a research which was conducted in the U.S.A. on black and white dolls for little children, where the black girls chose the white dolls because even in their thoughts and hearts they thought white was more beautiful than black and that this was a symbol for beauty.

(Translated from Hebrew)

The reactions of these students to the LL when they realized that Arabic was not dominant in their own neighborhood revealed feelings of discrimination, marginalization, and a lack of respect. It also created motivation among the students to change and transform their neighborhoods, and getting back to their families, discussing the issue of LL with them, and demanding a change for more Arabic representation in the public space. The study opened their 
eyes to things they had not noticed before about the community where they lived, creating a call for change.

The first implication of the Goldstein-Havazki study was the immediate connection between students' engagement with and documentation of real LL data in their neighborhoods and their growing awareness of the ways in which Arabic is silenced in the Jaffa landscape. The second implication was the students' insight that this silencing was not just a top-down policy, a simple effect of the state, but rather an internalized set of norms. They arguably, therefore, started to articulate an understanding of hegemony, in the Gramscian (1971) sense, referring to ways in which cultural modes of oppression may be internalized.

The third implication was that these concerns led the students to become more involved in policy and counter-hegemonic activity, questioning their parents and relatives, a process that some of them viewed as acts of betrayal of their collective and group identity. As we know from other forms of critical work, becoming aware of inequalities, discrimination, and one's own community's complicity with oppression (like women realizing that other women may be equally complicit in their subjugation) can be a necessary step towards emancipation, but it is neither a comfortable awareness nor a liberatory endpoint. Yet for community members to engage with actual LL data can bring about a demand for growing participation in questions of language policy and practice. LL as an act of engagement can turn students into concerned people with attention to language as a political and economic tool, and to activists in their communities as they become aware of the public space as an arena they "own" and should take control of.

\section{Encouraging activism}

Clearly, then, encouraging students to engage with the LL increased awareness of how the languages operate around them. This awareness, however, may also lead to a sense of helplessness in the face of the recognition that their presence has little symbolic acknowledgement. Awareness without a sense of possible action and change may be an unwelcome gift. This leads us to the third study (Shohamy et al. 2019), which was part of a larger project to develop a new multilingual policy in Israel (Shohamy and Tannenbaum 2019). The topic examined here was the development of students' multilingual awareness as well as their attentiveness to the possibilities of change, and the meaning of activism. Thus the question posed in this study was not merely one of helping students become aware of the LL, as in the two previous studies, but also to be able to change the signs and render them more socially just.

The study was conducted in three 11th-grade L2 classes: Two in Hebrewmedium schools in an English L2 class, and one in an Arabic-medium school, in a Hebrew L2. In addition to the ways in which students in the previous studies took pictures of their LLs and brought them back to class, here they 
were also encouraged to modify those signs in ways they found to be more socially just. These alterations, we should note, were digital alterations for discussion in class, rather than actual alterations to signs in the public sphere. There are limits we often need to draw in the process of developing a sense of critical activism among our students. Each LL teaching program took place over four sessions, each of 50 minutes, and taught by three teachers who had taken an LL course as part of their MA program at Tel Aviv University.

The following topics and activities were included: Students taking pictures of the LL in their environment; teachers introducing the LL concept; discussion of social issues and linking it to the LL examples; students sorting the pictures and critically analyzing them; selection of one picture they perceive as unjust and wish to modify; presentation in class of their modification along with the rationale for the change; submission of the before and after images and rationale for the change. The Hebrew L1 students wrote their reactions in English, while the Arabic-speaking students wrote in Hebrew. Figures 2.1 and 2.2 below display the format of what students submitted at the end of the four sessions: (a) The LL item that they perceived as being "unjust" to some group, (b) the new item which the student modified to become "just and inclusive,", and (c) an explanation of the rationale the student gave for the modification. In Figures 2.1 and 2.2 below, we see the format of the task.

The analysis of the data focused on the changes as well as the rationales provided by the students. This commonly, and not surprisingly, included the

\section{L1 Hebrew L2 English \\ Adding Arabic to signs}
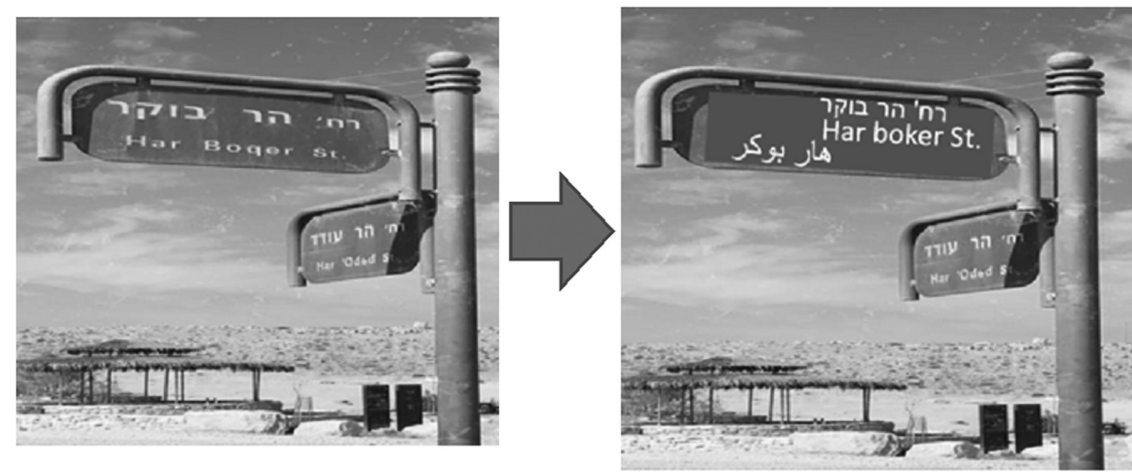

"Since in Israel we have Jews and Arabs, We would add a line in Arabic so (almost) all of the community in this place that concludes Arbs and Jews would be able to understand this sign and know where they are."

Figure 2.1: Hebrew speakers learning English. 


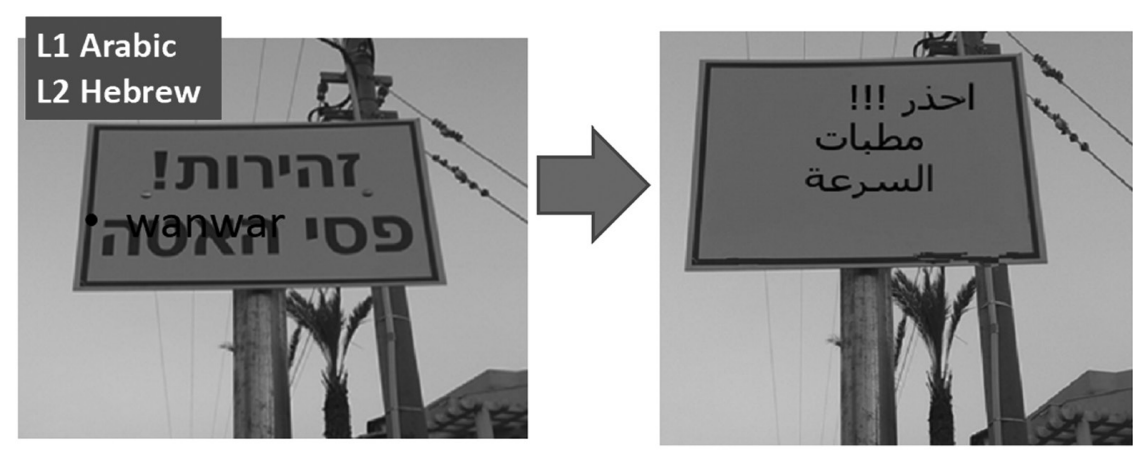

Warning sign in Hebrew

in an Arab town

changed to Arabic

Figure 2.2: Arabic speakers learning Hebrew.

addition of, or replacement by, Arabic to signs that included only Hebrew and English:

"Since $\mathrm{i}$ wanted to make a change on the sign because as $\mathrm{i}$ said at the beginning warning signs in an Arab town must be in the mother tongue of the residents of the town (An Arab town)."

(translated from Hebrew).

Student recommendations also involved the exclusion of signs, such as the suggestion to "remove the flag of Israel just because it makes the fans and some of the players feel that they are not related. Maybe this removal will make them feel better and not strangers in this game." Relative font size was also an issue: "We would add Hebrew to the sign in a big font and leave the English translation in a smaller font. In addition, we would add Arabic in a smaller font" (translated from Hebrew) (see Figure 2.2). Other suggestions included replacing a yellow button marked "stop" on a bus with what they saw as a more general symbol using a hand:

"In the original picture we don't like the fact that there is only the English language there ... [W] replaced the button with Stop sign because everybody knows what it means, it is also noticeable and can replace Hebrew, English, and Arabic together"

(translated from Hebrew). 
In general, all students in the study focused on language equality and marginalization, and they used the revised LL to protest against what they saw as inequality and injustice. How they perceived such injustices, however, varied considerably depending on their background. This is specifically demonstrated in the process of the pedagogical activity. Unlike the study by Shohamy and Abu Ghazaleh Mahajneh (2012), where students were given signs to which they reacted, in this project they themselves selected the signs that they viewed as unjust and then engaged in a process of modification. Students from the minority Arabic-speaking group tended to correct mistakes in Arabic texts. This was a common source of frustration and, as noted elsewhere (Yitzhaki, Tannenbaum and Shohamy 2020), students of Arabic background often showed irritation, not only at the absence of Arabic in their surroundings but also at the presence of what they saw as "deficient" Arabic. These students also occasionally deleted Hebrew or English and promoted Arabic instead. They also tended to focus more on issues such as domestic violence, racism, minority languages, multilingualism, and religion.

The students from the majority Hebrew-speaking group, by contrast, were more concerned with promoting various social issues, such as veganism, ecology, and the accessibility of signs. In Figure 2.3, for example, students from the Hebrew-medium school picked up on what they saw as a lack of forcefulness on a sign in a grocery store advocating for working "together for a greener life." These students wanted a stronger statement, suggesting greener living should be compulsory (a new law) rather

\section{L1 Hebrew L2 English \\ A Hebrew sign at a grocery store}
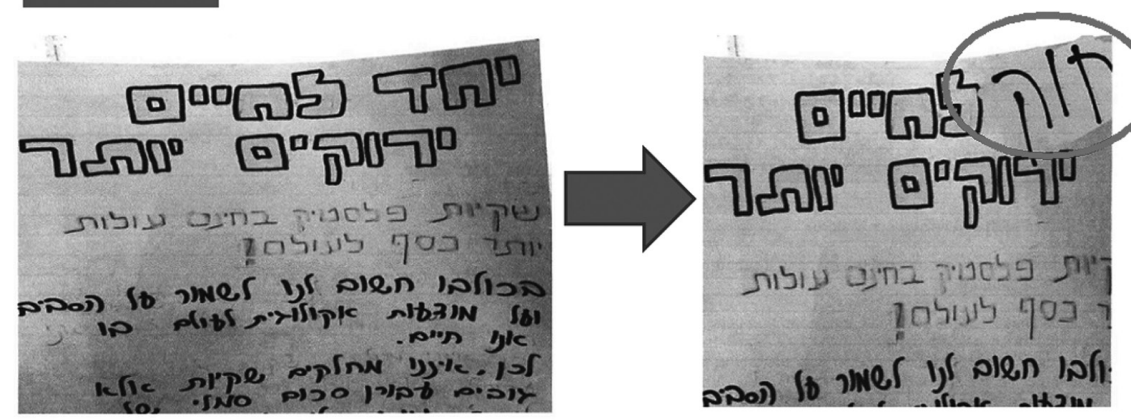

We would change the title of the sign from "together for a greener life" to "New law for a greener life" to clearly say this is a must and not upon anyone's choice.

Figure 2.3: New Law for a greener life. 


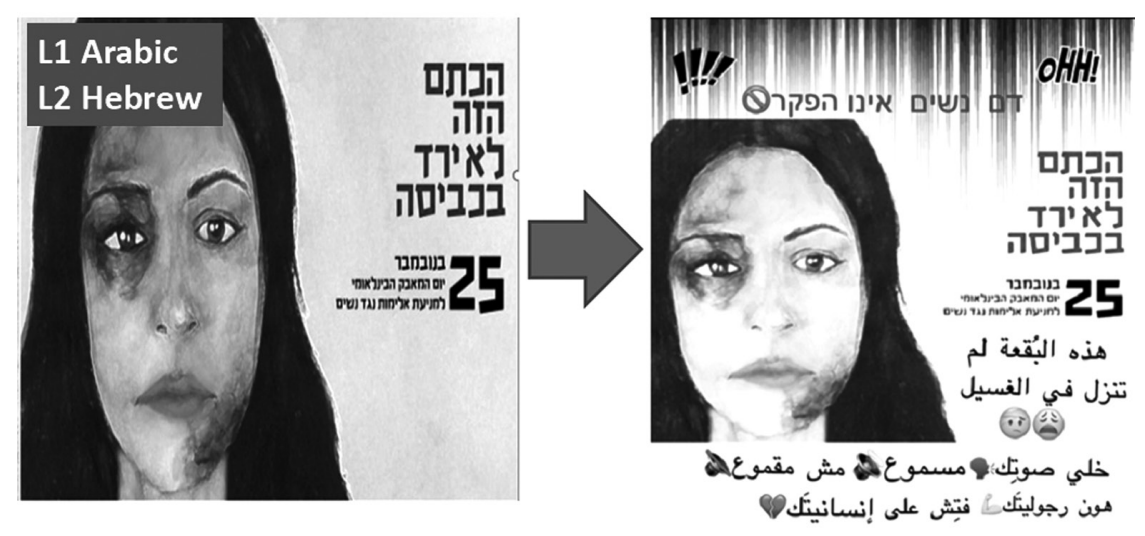

This stain will not wash off in the laundry. I felt that this sign protesting against violence towards women, written in Hebrew, is very relevant to our society as well and therefore I put it in Arabic (An Arab student (translated from Hebrew by ES).

Figure 2.4: This stain will not wash off.

than an option. In Figure 2.4, the students in the Arabic-medium school suggested adding Arabic to a sign drawing attention to domestic violence. Of particular significance here is the fact that the recommendation is not so much about linguistic inclusion (Arabic should be used more across public domains in Israel) but about an awareness that domestic violence is equally an issue in all communities. This suggests that alongside a concern for equal representation of Arabic was an awareness that domestic violence is an issue that overrides linguistic, ethnic, or religious differences.

This is not therefore the addition of Arabic as a form of civic inclusion ("Since in Israel we have Jews and Arabs, we would add a line in Arabic so (almost) all of the community in this place ... would be able to understand this sign and know where they are" [translated from Hebrew]) but rather the addition of Arabic to acknowledge a broader political struggle opposed to violence against women ("I felt that this sign protesting against violence towards women, written in Hebrew, is very relevant to our society as well, and therefore I put it in Arabic" [translated from Hebrew]). This is an important move politically - it is very different from the sense of shame discussed earlier that Arabic shopkeepers were using Hebrew rather than Arabic, since it suggests a move towards shared concerns around domestic violence. From this point of view, the failure to provide text in Arabic may mean that Arab-Israeli men may fail to see that the message is equally 
addressed to them. Along with different orientations towards different languages, there were different kinds of political awareness at play.

This program, which was aimed at teaching students to become aware of the LL in public spaces and to interpret the spaces in terms of justice, equality, inclusion, and other social issues, showed how students can become activists and agents of change. The act of modifying the LL, making some languages more visible, emphasizing various political dimensions as they relate to languages, and providing a strong and sensible rationale for the change indicate that high-school students can serve as agents of change for social issues in their environment. It also leads to a deeper understanding of public space and controversial real-life social issues, facilitating the development of competence in and for change. The program discussed in the third study suggests that "reading" the LL is an effective tool for noticing social and linguistic injustices. The novel procedure of modifying pictures and providing rationale for change, proves to be valuable for promoting awareness, and can lead to potential activism and change. This activity has implications for multilingual educational policies that can enhance students' awareness of issues, such as multilingualism, inclusion, acceptance, tolerance, and rights. This awareness went further than merely noticing languages in their environment; the program also enabled a deeper understanding of the public space and the controversial real-life social issues that are played out there.

\section{Awareness, activism, positionality, and gaze}

As discussed earlier, two of the important developments in LL research (alongside the semiotic and geopolitical expansions) have focused on the pedagogical roles the LL can play and the interpretive frames through which the LL is perceived. The studies discussed above raise several points for the pedagogical and interpretive engagement with LL. First, they shed light on the relationship between awareness and activism. This has long been a challenging concern in critical approaches to education (Pennycook 2021). From Paulo Freire's (1970) focus on conscientização (conscientization) to consciousness-raising work in feminist pedagogies, a key theme in critical pedagogy has been making people aware of the inequitable conditions of the world around them. Awareness is not an adequate goal in itself, however, since it may equally lead to a sense of hopelessness or surrender.

As Lewis (2018) reminds us, "error correction" (showing why certain beliefs about language are wrong, or, in this case, showing that languages are inequitably represented in the public space) will not do the necessary work towards social change without addressing the material conditions and social positions tied to those language inequalities. As noted in the first study (Shohamy and Abu Ghazaleh Mahajneh 2012), students observed the inequalities and discriminatory practices in the university context but felt powerless to do anything about them: This was just the way things were. Students came to perceive that this was how Hebrew hegemony operates 
and there was not much they could do about it. It was all very well to argue for respect and rights in relation to the use of Arabic, but the university LL - from signage to texts, from loudspeaker announcements to the medium of instruction - emphasized Hebrew and English, and there was little role for Arabic in this space. Beliefs that awareness may lead to action or emancipation assume too easily that students can find a pathway towards change.

Critical LL pedagogies therefore also need to help students develop a vision of social transformation, an alternative world worth striving for, as well as a means to develop activist orientations (Camangian 2015). Goldstein-Havazki's (2011) study showed the seeds of such change as high-school students started to see not only the inequalities of the Jaffa LL around them but also their own community's complicity in the reproduction of inequalities. These questions were addressed more explicitly in the Shohamy et al. (2019) study, which encouraged students towards forms of activism by asking them to suggest ways in which signs could be changed.

This is a critical pedagogy "that names, interrupts, challenges, critiques," and offers different possibilities for "language classrooms, curricula, schools, and communities that in turn affect societies and human life as a whole" (Gounari 2020, 5). The introduction of an activist dimension in this project encouraged students to think beyond a position of surrender. The possibility of modification in this study, by contrast, gave the students a chance to imagine a different world where public signs looked different, font sizes changed, and languages took on different roles. This stronger activist sensibility then informed wider discussions, in classrooms, within families, among friends, and across the wider communities.

These studies also draw attention to the importance of developing an understanding of positionality or gaze in relation to the landscape. It is evident that LL studies need to incorporate how the landscape is viewed from varying perspectives. As Woldemariam and Lanza (2012) make clear, for example, it matters not just that the Ethiopian Orthodox and protestant churches have a different presence in Addis Ababa, but also that this is viewed differently from different perspectives. Likewise, it became clear in the Shohamy et al. (2019) study that LL looked very different depending on the positionality of the viewer. It revealed clear differences in the perspectives from which these different groups viewed and proposed changes in the LL. From a more cognitivist perspective this could be interpreted as "different ways of seeing," as alternative schemas of interpretation, as different individual ways of reading the semiotic potential of the landscape. The different cultural, political, racial, and religious orientations at play here, however, suggest the need for a framework that is better attuned to the social positions from which the landscape is viewed.

Of importance here was not just the more commonplace observation that students of different backgrounds will likely notice different aspects of the landscape (the absence of Arabic, for example, is far more salient to students of Arab-Israeli than Jewish-Israeli background). What also became clear was 


\section{Elana Shohamy and Alastair Pennycook}

that students from a minority background - and who clearly saw themselves in these terms - viewed the LL from a perspective that went further than just the noting of inequitable language representation. Drawing on Inoue's (2006) emphasis on the "listening subject," and its take up by Lo and Reyes (2009) and Rosa (2019) to show that the gaze of the perceiver matters fundamentally in the ways language varieties are perceived, we need to move away from a belief that the LL exists in the environment waiting to be perceived. The LL, rather, is constituted by the gaze of the viewers, and their sociopolitical positionality matters fundamentally in that process of perception.

Drawing on the concept of "raciolinguistic enregisterment" (Rosa and Flores 2017, 631), which points to the ways in which language and race are combined in the perception of language use, we are interested here in the ways in which the landscape is viewed in very different terms by students of different backgrounds. This is not an individual effect (everyone sees the landscape from their own perspective), nor an equality of effect (each group has its own view), but rather a sociopolitical effect whereby the LL is viewed along different lines depending on the positionality of the student. While this positionality may indeed reflect the linguistic, cultural, and religious divides that run through Israel, there is also more complexity here. When one student remarked that there should be Arabic on the sign drawing attention to violence against women - on the grounds that this was equally a concern for her community as for the majority to whom it seemed to be addressed - she was raising concerns about language, gender, and community that transcend easy assumptions about a student gaze based purely on linguistic or ethnic lines.

\section{Conclusions}

Within the pedagogical and interpretive focus of LL, we have highlighted the need to develop a clearer and more critical focus on the locus of the gaze in the LL: Who is looking from what position informed by what relations of class, race, gender, ethnicity, religion, language, and so on? The challenge is to understand and build into any understanding of LL research and pedagogy the lines along which the same landscape may become radically different according to who is looking. High-school students from Hebrew schools can see the LL politically but in ways that are marked by their majority ethnic and class positions. Students from Arabic schools see a different LL and have different suggestions as to how it might be changed. This both reveals the different ways in which the LL is understood and also suggests scope as a further site of discussion and educational benefit, revealing to each group the others' sensitivities. There is the potential in such work for the majority group to become aware of what is perceived as unjust for the minority, while the minority can start to understand what matters (and doesn't) for the majority.

Finally, we also want to draw attention to another, subsequent dimension of this project: The importance of "closing the LL circle," by which we mean 
taking the landscape back to the streets (or at least to public spaces), and of introducing this work to a new audience through public displays. One might, of course, simply hand our students some spray paint and urge them to be activists: Go forth and change the landscape. This might understandably cause some concern in both educational and municipal circles (though the possibilities graffiti offer as a challenge to perceptions of the public and private should not be underestimated). Instead, the project has moved back into the public sphere as a public exhibition. Following the work done by the Center for Multilingualism in Society across the Lifespan in taking work on Multilingual Oslo and Multilingual Mothers into the public domain through exhibitions in museums and elsewhere, During the months of March 2020 and August, 2021 an exhibition of 15 signs of students signs - as is, modified and interpreted, in Hebrew, Arabic and English were displayed at the Social Science library -at Tel Aviv University. The goal was to expose this research to the public and to see how they react to student suggestions for change.

\section{References}

Alim, H.S. 2005. "Critical Language Awareness in the United States: Revisiting Issues and Revising Pedagogies in a Resegregated Society." Educational Researcher 34: 24-31.

Blackwood, R., E. Lanza, and H. Woldemariam, eds. 2016. Negotiating and Contesting Identities in Linguistic Landscapes. London: Bloomsbury.

Blommaert, J. 2005. Discourse: A Critical Introduction. Cambridge: Cambridge University Press.

Blommaert, J. 2013. Ethnography, Superdiversity and Linguistic Landscapes: Chronicles of Complexity. Bristol: Multilingual Matters.

Camangian, P. 2015. "Teaching Like Lives Depend on It: Agitate, Arouse, Inspire." Urban Education 50, no. 4: 424-453.

Dagenais, D., D. Moore, C. Sebastier, P. Lamarre, and F. Armand 2009. "Linguistic Landscape and Language Awareness." In Linguistic Landscape: Expanding the Scenery, edited by E. Shohamy and D. Gorter, 253-269. New York: Routledge.

Freire, P. 1970. Pedagogy of the Oppressed. Translated by M. B. Ramos. New York: Continuum.

Goldstein-Havetzki, R. 2011. "A Travel Diary in Jaffa: Development of Linguistic Landscape Awareness and Attitudes among Teenagers." Unpublished MA thesis, Tel Aviv University.

Gorter, D., and J. Cenoz. 2015. "Linguistics Landscape in Multilingual Schools." In Challenges for Language Education and Policy, edited by B. Spolsky, O. InbarLourie, and M. Tannenbaum, 151-169. New York: Routledge.

Gounari, P. 2020. "Introduction to the Special Issue on Critical Pedagogies." L2 Journal 12, no. 2: 3-20.

Gramsci, A. 1971. Selections from the Prison Notebooks of Antonio Gramsci. New York: International Publishers.

Hayik, R. 2017. "Exploring the Perceptions of Passers-by Through the Participatory Documentary Photography Tool Photo Voice." Linguistic Landscape 3, no. 2: $187-212$. 
Inoue, M. 2006. Vicarious Language: Gender and Linguistic Modernity in Japan. Berkeley: University of California Press.

Karlander, D. 2018. “Backjumps: Writing, Watching, Erasing Train Graffiti.” Social Semiotics 28, no. 1: 41-59.

Lanza, E., and H. Woldemariam. 2014. "Indexing Modernity: English and Branding in the Linguistic Landscape of an African Capital." International Journal of Bilingualism 18, no. 5: 491-506.

Lewis, M. 2018. "A Critique of the Principle of Error Correction as a Theory of Social Change." Language in Society 47, no. 3: 325-346.

Lo, A., and A. Reyes. 2009. "On Yellow English and Other Perilous Terms." In Beyond Yellow English: Toward a Linguistic Anthropology of Asian Pacific America, edited by A Reyes, and A. Lo, 3-17. New York: Oxford University Press.

Lou, J. J. 2017. "Spaces of Consumption and Senses of Place: A Geosemiotic Analysis of Three Markets in Hong Kong.” Social Semiotics 27, no. 4: 513-531.

Malinowski, D. 2009. "Authorship in the Linguistic Landscape: A MultimodalPerformative View." In Linguistic Landscape: Expanding the Scenery, edited by E. Shohamy, and D. Gorter, 107-125. London: Routledge.

Malinowski, D. 2015. "Opening Spaces of Learning in the Linguistic Landscape." Linguistic Landscape 1, no. 1/2: 95-113.

Menken, K., P. Rosario, and V. Guzman Valerio. 2018. "Increasing Multilingualism in Schoolscapes." Linguistic Landscape 4, no. 2: 101-127.

Peck, A., and C. Stroud. 2015. "Skinscapes." Linguistic Landscape 1, no. 1/2: 133-151.

Pennycook, A. 2009. "Linguistic Landscapes and the Transgressive Semiotics of Graffiti." In Linguistic Landscape: Expanding the Scenery, edited by E. Shohamy, and D. Gorter, 302-331. New York: Routledge.

Pennycook, A. 2019. "The Landscape Returns the Gaze: Bikescapes and the New Economies." Linguistic Landscape 5, no. 3: 217-247.

Pennycook, A. 2021. Critical Applied Linguistics: A Critical Re-introduction (Second edition). New York: Routledge.

Pennycook, A., and E. Otsuji 2015. "Making Scents of the Landscape." Linguistic Landscape 1, no. 3: 191-212.

Rosa, J. 2019. Looking Like a Language, Sounding Like a Race: Raciolinguistic Ideologies and the Learning of Latinidad. New York: Oxford University Press.

Rosa, J., and N. Flores. 2017. "Unsettling Race and Language: Toward a Raciolinguistic Perspective." Language in Society 46, no. 5: 621-647.

Shohamy, E. 2015. "LL Research as Expanding Language and Language Policy." Linguistic Landscape 1, no. 1/2: 152-171.

Shohamy, E., and M. Abu Ghazaleh Mahajneh. 2012. "Linguistic Landscape as a Tool for Interpreting Language Vitality: Arabic as a 'Minority' Language in Israel." In Minority Languages in the Linguistic Landscape, edited by D. Gorter, H. F. Marten, and L. Van Mensel, 89-106. Basingstoke: Palgrave-Macmillan.

Shohamy, E., and M. Tannenbaum. 2019. A New Multilingual Policy for Israeli Schools. Final Report Submitted to the Ministry of Education. Chief Scientist Office, October, 2019 (in Hebrew), Tel Aviv University, Tel Aviv.

Shohamy, E., M. Tannenbaum, I.I. Or, I. Or, I. H. J. Solomon, S. Naaman, M. Trijnes, and S. Haj Yehia. 2019. Researching the Use of Linguistic Landscape for Enhancing Multilingual Awareness and Activism in Schools. Paper presented at the 12th LL workshop. Bangkook, June. 
Shohamy, E., and S. Waksman. 2009. "Linguistic Landscape as an Ecological Arena: Modalities, Meanings, Negotiations, Education." In Linguistic Landscape: Expanding the Scenery, edited by E. Shohamy, and D. Gorter, 313-333. New York: Routledge.

Trumper-Hecht, N. 2010. "Linguistic Landscape in Mixed Cities in Israel from the Perspective of 'Walkers': The Case of Arabic." In Linguistic Landscape in the City, edited by E. Shohamy, E. Ben Rafael, and M. Barni, 235-251. Bristol: Multilingual Matters

Waksman, S., and E. Shohamy. 2016. "Linguistic Landscape of Social Protests: Moving from 'Open' to Institutional Spaces." In Negotiating and Contesting Identities in Linguistic Landscapes, edited by R. Blackwood, E. Lanza, and H. Woldemariam, 85-98. London: Bloomsbury.

Williams, Q., and E. Lanza. 2016. "The Visualisation of Multilingualism and Voice in Spaces of Consumption: Linguistic Landscaping in a South African Urban Space." In Negotiating and Contesting Identities in Linguistic Landscapes, edited by R. Blackwood, E. Lanza, and H. Woldemariam, 233-249. London: Bloomsbury.

Woldemariam, H., and E. Lanza. 2012. "Religious Wars in the Linguistic Landscape of an African Capital." In Linguistic Landscape in the City, edited by E. Shohamy, E. Ben Rafael, and M. Barni, 169-186. Bristol: Multilingual Matters.

Yitzhaki, D., M. Tannenbaum, and E. Shohamy. 2020. “'Shared Education' and Translanguaging; Students at Jewish and Arab Schools Learning English Together." International Journal of Bilingual Education and Bilingualism. doi: 10.1080/13670050.2020.1740164 
